INTERNATIONAL JOURNAL OF RESEARCHES IN BIOSCIENCES, AGRICULTURE AND TECHNOLOGY (C) VISHWASHANTI MULTIPURPOSE SOCIETY (Global Peace Multipurpose Society) R. No. MH-659/13(N) www.vmsindia.org

\title{
ROLE OF NUTRIENTS AND AQUATIC VEGETATION IN EUTROPHICATION AND SUCCESSION OF WATER BODIES
}

\author{
R. V. Tijare $^{1}$ and P. M. Telkhade ${ }^{2}$ \\ ${ }^{1}$ Institute of Science, Civil Lines, Nagpur \\ ${ }^{2}$ Arts, Commerce \& Science College, Tukum, Chandrapur
}

\begin{abstract}
:
The term eutrophication refers to the change in a lake from having lower level of primary productivity to a higher level of primary productivity. The eutrophication of several water bodies leads to significant changes in the structure and function of the aquatic ecosystem. Most of the water bodies over the world are surrounded with densely populated human settlement areas and agricultural fields. In addition to nutrients several environmental factors have also responsible for eutrophication. The change in eutrophic conditions is reflected in the occurrence, pattern of distribution and diversity of the biotic community. Eutrophication caused by human influences typically occurs over decades and results in the excess growth of algae and plants, reduces water clarity, light penetration and oxygen concentrations which can have impacts on aquatic life. Workers like Adoni (1985), Ansari (2002), Gerg (1998), Kant \& Raina (1990), Kaul (1970), Kulshreshtha et al. (1989), Mishra et al. (1975), Tripathi (1990), Trisal (1983), Khan (2005) and Tijare (2011) worked on various nutrients and aquatic plants responsible for eutrophication of water bodies present in India. Eutrophication, or the promotion of the growth of plants, animals, and microorganisms in ponds, lakes and rivers, has been a very slow, natural process. Succession is the process by which a waterbody becomes a marsh, then a bog, and finally a drier terrestrial body. Human activities around the aquatic bodies have enhanced the nutrient input. Phosphorus and many nutrients have key role in eutrophication and finally in succession. Succession is a dynamic and continuous process, often occurring gradually in due course and leads to change in species composition, age and size, ecosystem structure and their function.
\end{abstract}

Key words: Nutrients, aquatic plants, eutrophication and succession.

\section{Introduction:}

Aquatic plants contribute to maintaining key functions and related biodiversity in freshwater ecosystems, and to provide the needs of human societies. Most aquatic species are phylogenetically descended from terrestrial plants that have later adapted to aquatic life. Water plants are usually poorly lignified, as water preserves plants from gravitational stress, and are characterized by the presence of aerenchyma, which increases oxygen flux from shoots to roots, and by a large leaf surface, together with a thin cuticle, which increase contact with water and carbon uptake.

In freshwater ecosystems, the production, community composition and life-history traits of macrophytes are governed by the availability of carbon, nitrogen and phosphorous. Free-floating and tall species with floating leaves are the most competitive for light, and usually dominate macrophyte communities when nutrient levels in the water are sufficiently high. Several activities of human interest, including navigation and power generation, are hampered. A large number of water bodies in the United States, Europe, and Asia have recently been found to be in highly eutrophic condition. Most of the water bodies of world are surrounded with densely populated human settlement areas and agricultural fields. The size of smaller water bodies in human settlement areas is on the decrease with rise in population. Several environmental factors have also been found to add to the problem of eutrophication in addition to nutrients. The limiting factors like $\mathrm{CO}_{2}$, temperature, $\mathrm{pH}$, light, and dissolved oxygen are also affects on eutrophication of water bodies.

The studies on the change in structure, function, and diversity of the ecosystem have been used as parameters to assess the level of eutrophication. In many countries adequate control measures have been adopted in to control eutrophication but these measures were found to be only partially effective in controlling the phosphorus unloading in water bodies. Climate change and pollution are global problems which affects the waterbody largely or partially (Beeton, 2002). The death and decay of aquatic plants produces a foul smell and makes the water more turbid (Beeby, 1995; Rao, 1998). Eutrophication, or the promotion of the growth of plants, animals, and microorganisms in lakes and rivers, has been a very slow, natural process. If this is allowed to occur uninterrupted, it results in an excessive deficiency of oxygen in the water. Thus organisms that flourish under anaerobic conditions are favored more and more at the 
expense of aerobic organisms (Mengel \& Kirkby, 1996).

The change in eutrophic conditions is reflected in the occurrence, pattern of distribution, and diversity of the biotic community (Tiwari, 1998). The decomposers use up the dissolved oxygen of the water body. The dissolved oxygen concentrations often drop too low for fish to breathe causing mortality. Garg et al. (2002) studied three lakes of Bhopal (Upper Lake, Lower Lake, and Mansarovar Lake) in India, to assess the potential fertility of lentic waters and to analyze the floral ecology. The highest level of eutrophication was found in Mansarovar Lake. The addition of effluents from urbanized Bangalore city has changed the characteristics of the lake from a natural, oligotrophic lake to an artificial reservoir of domestic sewage and industrial effluents (Chandrashekar et al., 2003). Singhal and Mahto (2004) studied the characteristics Robertson Lake in the urban area of Jabalpur, India and found low species density, fast shallowing, dominance of detritus food webs, and water unsuitable for human consumption. To gain more insight into the gravity of damage caused by eutrophication to our depleting water resources, a brief account of the ecological aspects of distribution and water cycle is given herewith.

\section{Role of nutrients in eutrophication:}

The natural phosphorus cycle originating from the weathering of phosphate rock is now a two-way operation, due to significant addition of phosphorus from anthropogenic sources. The detergents are the major source of phosphorus inputs into water bodies through sewage and drainage systems. The major part of detergents comprises builders containing polyphosphate salts. An environment-friendly and effective synthetic builder is yet to be developed to replace existing phosphorus containing builders of detergents. After treatment, a large quantity of sewage from the households is regularly discharged into the water bodies. The runoff brings down fertilizers and other chemicals from agricultural fields. The phosphorus contained in these effluents is known to promote excessive growth of plants.

If excessive amounts of phosphorus and nitrogen are added to the water, algae and aquatic plants can grow in large quantities. When these algae die, they are decomposed by bacteria. The nutrient unloading into the waterbodies initially promoted the growth of phytoplanktons. The higher concentration of nutrients in certain pockets of the lake, due to increased human influences spoiled the quality of potable water (Jha and Barat, 2003). Nitrogen has also been reported to affect the phytoplankton production in eutrophic waters in temperate regions.

In freshwater systems phosphorus has been identified as the "limiting nutrient" to phytoplankton development. This nutrient is mainly brought to aquatic environment from the weathering of rocks, the leaching of soil, and rain. The major part of phosphorus is unloaded into aquatic bodies from agricultural runoff and domestic sewage. The phosphate is a relatively immobile element and may be carried to streams through soil erosion and storm runoffs from over fertilized or excessively fertilized agricultural fields, nurseries, lawns, and orchards. Certain synthetic chemicals, such as pesticides, construction materials, flame retardants, and plasticizers, are the other sources of phosphate discharges. Garg et al. (2002) studied three lakes of Bhopal i.e. Upper Lake, Lower Lake, and Mansarovar Lake in India and assessed the potential fertility of the lentic water and its aquatic flora and observed highest eutrophication in Mansarovar Lake. These observations indicated that different species of phytoplankton could subsist up to a certain nutrient level, beyond which competition between cyanophytes and other algae enhanced and eliminated the sensitive plankton flora.

Role of aquatic vegetation and succession:

Eutrophication not only results in algal bloom but also affects wetland plants and activates early onset of natural succession at a relatively faster rate. Some of the plant species reported and studied world over are the best indicators of the level of eutrophication.

The changes in an ecosystem that follow a disturbance are collectively called succession; it is a dynamic and continuous process, often occurring gradually and there is a change in species composition, age, size, and ecosystem structure and function in due course. Primary succession occurs in environments that lack organic matter and which have not yet been altered in any way by living organis ms. Primary succession includes the development over time of the original substrate into a soil, and occurs over centuries while secondary succession occurs in an environment that has supported mature vegetation in the past, and where, after the disturbance in soil remains relatively intact. Waterbody undergoes physical aging finally and become filled with sediment and particulate matter causing it to become shallower. The two main factors that control the succession are the 
mean depth of the waterbody and the addition of nutrients from the surrounding drainage basin. The waterbodies will filled with sediments and particulates deposited from various processes and gradually waterbody can change into a wetland or even to a dry land environment. Succession is the process by which a water body becomes a marsh, then a bog, and finally a drier terrestrial body. Human activities around the aquatic bodies have enhanced the nutrient input rate and accelerated the natural aging process known as "eutrophication." This aging process brought down the water body under a faster cycle of succession (Reutter, 1989). Eutrophication is a noticeable problem of aquatic environments all over the world. In the Netherlands, the abundance of many aquatic macrophytes has shown a steep decline, and the eutrophic habitats are now characterized by floating species like Lemna, Spirodela, and Azolla.

Bioindicators act as a measure of prevailing environmental conditions. Also referred to as "ecological indicators," bioindicators provide information on the ecosystem condition. They may be used to observe the functioning and cause-and-effect relationships within an ecosystem. The biological indicator of eutrophication may be a single species or an assemblage of several species. The diversity and distribution of species in an ecosystem depends upon the ecological amplitude of species and the existing environment of the ecosystem. Some of the biological parameters are given below. Algae are commonly used for biological assessment of water quality and indicators of eutrophication (Garg et al., 2003; Patrick, 1950). Growth and continuous blooms of Microcystis and presence of Stigeoclonium leads to organic pollution in Banjara Lake, in India (Swaranlatha \& Rao, 1998). Adoni and Yadav (1985) also focused on chemical and productional characteristics of Potamogelon pectinutusn and Hydrilla verticillata in a eutrophication of lake. Some aquatic macrophytes are known as bioindicators of eutrophication. Vallisnaria is reported as the efficient biomonitor of organic contamination and stressed aquatic ecosystems. Some important bioindicators of eutrophication are Wolffia sps., Lemna sps., Typha sps., Spirodela polyrrhiza, Ceratophylum sps, Elodea sps. and Phragmites sps. These are the best indicators of eutrophication of water bodies caused by organic effluents and nutrients (Stojanovic et al., 1998). The growth of Spirodela polyrriza was found to be directly related to the nutrient concentration of water (Ansari \& Khan, 2002). The population and growth of Lemna and Spirodela were studied as a measure of eutrophication caused by household detergents (Ansari, 2005). The diatom assemblage in water bodies indicates eutrophication by nitrogen and phosphorus concentrations (Denys, 2003; Winter \& Duthie, 2000). The changes in geochemistry and diatom assemblages are probably linked to increases in nutrient supply, increases the primary production (Gibson et al., 2003).

\section{Conclusion:}

Day by day rapid eutrophication has leads to significant changes in water quality as well as results in physical, chemical, biological, and ecological changes in water bodies. The studies on eutrophication have revealed that the nutrient inputs into shallower and warmer parts of lakes are more severely altered (Reutter, 1989). Enrichment of nutrients in a water body accelerates its aging process and leads to faster succession

Water bodies located near large cities are likely to receive more phosphorus from domestic effluents containing detergents. However, urban water bodies also receive major quantities of phosphorus from fertilizers and other agriculture-related activities. Eutrophication of smaller water bodies reduce the water-recharging capacity in these areas, so groundwater is likely to become depleted partly due to eutrophication and partly due to exploitation through pumping. Eutrophication of water bodies alters the physicochemical properties of water, the diversity of aquatic flora and fauna. The main cause of eutrophication process is overloading and cycling of nutrients like phosphorus. The overall outcome of eutrophication in terms of reduction in size and depth of water bodies leads into succession.

Some effective control measures, including awareness programs pertaining to the present threat to water resources on the blue planet need to be implemented. The phosphorus input from one of the two sources i.e. natural erosion of phosphate rocks and anthropogenic sources such as detergents and fertilizers needs to be checked. The main importance needs to be on controlling excessive phosphorus inputs from the anthropogenic source. A check on the excessive erosion of phosphate rocks, probably due to deforestation, is also required. The depletion of the water resource may be checked if efforts are made at international and local government levels to adopt legislative measures and develop an alternative phosphorus-free 
detergent builder. Awareness and educational programs at government and nongovernmental organization levels would be much more effective than mere legislative measures.

\section{References:}

Adoni, A. D. \& M. Yadav (1985). Chemical and productional characteristics of Potamogelon pectinutusn (Linn.) and Hydrilla verticillata (Royle) in a eutrophic lake. Proceedings of the National Symposium on Pure and Applied Limnology. Bulletin of Botanical Society,Univ. of Sagar. Pp. 96 $-105$.

Ansari, A. A. and E A. Khan. (2002). Nutritional status and quality of water of a waste water pond in Aligarh showing blooms of Spirodela polyrrhiza (L.) Shleid. Journal of Ecophysiology and Occupational Health 2: 185-189.

Ansari, A. A. (2005). Studies on the role of selected household detergents in the eutrophication of freshwater ecosystem. Ph.D. diss., Aligarh Muslim Univ.

Beeby, A., (1995). Applying ecology. Chapman \& Hall, London.

Beeton, A. M., (2002). Large freshwater lakes: Present states, trends and future. Environmental Conservation 29: 21-38.

Chandrashekar, J. S., K. Lenin Babu \& R. K. Somashekar. (2003). Impact of urbanization on Lake and catchment management in Denmark. Hydrobiologia 395-396: 41\%432.

Denys, L. (2003). Environmental changes in manmade coastal dune pools since 1850 as indicated by sedimentary and epiphytic diatom assemblages (Belgium). Aquatic Conservation 13:191-211.

Garg, S. K. (1998). Sewage disposal and air pollution engineering: Environmental engineering. Ed. 11. Khanna Publications, Delhi.

Garg, J., H. K. Garg \& J. Garg. (2002). Nutrient loading and its consequences in a lake ecosystem. Tropical Ecology 43: 355-358.

Garg, J., H. K. Garg \& J. Garg.(2003). Algae as indicators of eutrophication: A microcosmal approach. Environment and Ecology 21 : 313316.

Gibson, C. E., N. J. Anderson, Q. Zhou, M. Allen \& P. G. Appleby. (2003). Changes in sediment and diatom deposition in Lower Lough Eme c. 192( 90. Biology and Environment 103B: 3138.

Jha, E \& S. Barat. (2003). Hydrobiological studies of Lake Mirik in Darjeeling Himalayas. J. Env. Biol. 24: 339-344.

Khan, F.A. \& A.A. Ansari, (2005). Eutrophication: An Ecological Vision, The Botanical Review 71(4): 449-482.

Kant, S. \& A. K. Raina. (1990). Limnological studies of two ponds in Jammu, II. Physicochemical parameters. J. Env. Biol. 11:137 144.
Kaul, V. (1970). Production and ecology of some macrophytes of Kashmir lakes. Hydrobiologia 12: $63 \sim 59$.

Kulshreshtha, S. K., R. Saxena, M. P. George, M. Srivastava \& A. Tiwari. (1989). Phytoplankton of eutrophic Mansarovar reservoir of Bhopal. International Journal of Ecology \& Environmental Science 15: 205 15.

Mengel, K. \& E. A. Kirkby. (1996). Principles of plant nutrition. Ed 4. Panima Publishing Corp., New Delhi.

Misra, S. D., S. C. Bhargava \& O. E Bohra. (1975). Diurnal variation in physico-chemical factors at Padmasagar reservoir during premonsoon period of the year 1974. Geobios 2: 3233.

Patrick, R. (1950). Biological measure of stream conditions. Sew. Industr. Wastes 22: 926-938.

Rao, C. S. (1998). Environmental pollution control engineering. New Age International, New Delhi.

Reutter, J. M. (1989). Lake Erie: Phosphorus and eutrophication. Fact Sheet 015. Ohio Sea Grant College Program, Columbus.

Sharma, P. D. (1998). Ecology and environment. Rastogi Publications, Meerut.

Stojanovic, S., L. Nikilic \& D. Lazic. (1998). The function of dominant hydrophytes of the Mostonga (Serbia Yugoslavia) in water quality bioindication. Pp. 425-428 in Proceedings of the 27th Annual Conference of Yugoslav Water Pollution Control Society, Beograd (Yugoslavia).

Swaranlatha, N. \& A. N. Rao. (1998). Ecological studies of Banjara Lake with reference to water pollution.J. Env. Biol. 19: 179-186.

Tijare, R.V. (2011). Study of macrophytic vegetation present in the lentic waterbodies of Gadchiroli, M.S. (India). Golden Research Thoughts Vol. 1 (4): pp $64-65$.

Tiwari, A. (1998). Rotifers as indicators for assessment of water quality. Proc. Acad. Environ. Biol. 7:161-166.

Tripathy, E K. \& S. E Adhikary. (1990). Preliminary studies on the water pollution of river Nandira. Indian Journal of Environmental Health 32: 363-368.

Trisal, C. L. \& S. Kaul.(1983). Sediment composition and water inter changes and the role of macrophytes in Dal Lake, Kashmir. Hydrobiologia 68:671-682. 